\title{
An Overview of Methods for Testing Short- and Long-Run Equilibrium with Time Series Data: Cointegration and Error Correction Mechanism
}

\author{
Ferdinand Niyimbanira \\ Lecturer in Economics \\ Faculty of Management Sciences \\ Vaal University of Technology \\ Private Bag X021, Vanderbijpark, 1900 \\ Email: ferdinandn@vut.ac.za, Tel: 016-9509194
}

Doi: 10.5901/mjss.2013.v4n4p151

\begin{abstract}
Time series data are usually with a natural temporal ordering. This makes time series analysis distinct from other common data analysis problems, in which there is no natural ordering of the observations. This paper is about the methods used in economics when analyzing time series data. It shows the steps of testing for stationarity where unit root tests in which the Dickey-Fuller and Augmented Dickey-Fuller tests are discussed. For cointegration, Durbin-Watson, Engle-Granger and Augmented Engle-Granger tests are presented step by step. This paper does not end with the analysis of cointegration tests only, but it proceeds to error correction methods which is usually used to make adjustments in a dependent variable which depends not on the level of some explanatory variable, but to the extent to which an explanatory variable deviates from an equilibrium relationship with the dependent variable and half-life formula is introduced to show how long it may take for readjustment to equilibrium. With all discussions, policy implications and suggestions for future research are made in the paper.
\end{abstract}

Key Words: Cointegration, Error Correction Mechanism, Time Series and Unit Root

\section{Introduction}

The purpose of this paper is to present the methodology used in economics when one is conducting a research with time series data. Researchers can analyse time series data erroneously by formulating a traditional regression model to represent the behaviour of data but not pay too much attention to the specification of the dynamic structure of the time series. One also needs to worry about simultaneity bias and autocorrelated errors. Time series data are assumed by econometricians to be non-stationary (Kennedy, 1996). In other words, time series data do not have a fixed stationary mean. Therefore, running a regression on non-stationary data may give misleading values of $\mathrm{R}^{2}$, DW and $t$ statistics; and this leads to the incorrect conclusion that a meaningful relationship exists among the regression variables, when it does not (Kennedy, 1996, p.263). To solve this problem of spurious results, one uses the method of cointegration. Indeed, the method of cointegration is used to estimate the long-run equilibrium, while the error correction mechanism (ECM) should be applied to estimate the short-run dynamics of the model. After collecting data, specifying research model (mathematical and econometric model) one needs to proceed to the hypothesis testing.

According to Hawkins and Weber (1980, p.45), "a time series is a sequence of observations taken on some process that varies over time." This type of data poses many challenges to researchers, especially econometricians. One may ask why? The key problem is between data being stationary and non-stationary. Most empirical work based on time series data assumes that the underlying time series data is stationary, or its mean and variance do not fluctuate systematically over time (Gujarati, 2003, p.26). However, it is known that many macroeconomic time series data are nonstationary (Hill, Griffiths and Judge, 2001). Most economic time series are generally integrated of order one I(1) and become stationary only after taking first differences. One may ask what the problem with non-stationary data is. The answer is that "when time series are used in a regression model the results may spuriously indicate a significant relationship when there is none" (Hill et al., 2001, p.340). To check for stationarity, there are different tests one can use. 


\section{Checking for Stationarity}

It is advisable, as a first step, to plot the data under study before the researcher pursues formal tests to check variables for stationarity. This gives an initial idea about the likely nature of the time series (Gujarati 2003, p.807). It is preferable to use natural logarithms when plotting regression variables in order to show their growth. However, it should be noted that looking at time series plots alone is not enough to tell whether a series is stationary or non-stationary. The autocorrelation function at lag $k$, denoted by $\rho_{k}$, is defined as the covariance at lag $k$ divided by the variance. A Plot of $\rho_{k}$ versus $k$ is known as the sample or population correlogram (Gujarati, 2003, p.808). One denotes $k$ as the lag length when computing the sample autocorrelation function. According to Shumway and Stoffer (2000, p. 26), "the autocorrelation function has a sampling distribution, under complete independence, which allows us to assess whether the data comes from a completely random or white series or whether correlations are statistically significant at some lags." Hence, if a time series is stationary, the autocorrelation coefficient at various lags will remain around zero and decline quickly, while in a non-stationary time series the autocorrelation coefficient starts at a high value and declines very slowly towards zero as the lag lengthens (Gujarati, 2003, p.810-811).

The population correlogram is defined as follows:

$$
\begin{aligned}
\rho_{k} & =\gamma_{k} / \gamma_{0} \\
& =\text { covariance at lag } \mathrm{k} / \text { sample variance. }
\end{aligned}
$$

If $k=0$, $\rho_{0}$ will be equal to 1 . However, only an estimation of the sample autocorrelation function ${ }^{{ }^{k}}$ can be worked out. According to Gujarati (2003), this requires one first to compute the sample covariance at lag $k$, $\hat{y}_{k}$; and the sample variance, $\hat{y}_{0}$, and are represented by the following equations:

$$
\begin{aligned}
& \hat{y}_{k}=\sum\left(y_{t}-\bar{y}\right)\left(y_{t+k}-\bar{y}\right) / n \\
& \hat{y}_{0}=\sum\left(y_{t}-\bar{y}\right)^{2} / n
\end{aligned}
$$

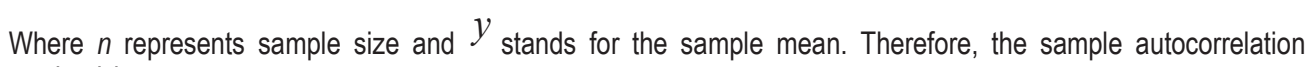
function at lag $k$ is:

$$
\hat{\rho}_{k}=\hat{y}_{k} / \hat{y}_{0} .
$$

\section{[4]}

The above statement should be for the correlogram of some of the variables may reveal themselves to be nonstationary, while others show a subjective probability that the data series may be stationary.

\section{Unit Root Test}

When discussing stationary and non-stationary time series, an alternative test, which has recently become popular, is known as the unit root test. This test is important as it helps to avoid the problem of spurious regression. In defense of this point, Harris (1995, p.27) writes that "if a variable contains a unit root then it is non-stationary and unless it combines with other non-stationary series to form a stationary cointegration relationship, then regression involving the series can falsely imply the existence of a meaningful economic relationship." Testing for the presence of unit roots is not straightforward, but the easiest way to introduce this idea is to consider the following equation: 


$$
y_{t}=y_{t-1}+u_{t}
$$

And $u_{t}$ in the equation is the stochastic error term or white noise error term. There are several ways of testing for the presence of unit root. This study uses the Dickey-Fuller (DF) and Augmented Dickey-Fuller (ADF) tests for testing the null hypothesis that a series does contain a unit root or is non-stationary. Both the DF and ADF approaches are developed from equation 5 . One needs to consider these tests in more detail, by developing 5 .

\section{Dickey-Fuller Test (DF)}

If a series is differenced $d$ times, for example, before it becomes stationary, then it is said to be integrated of order $d$, and is denoted $I(d)$. If a series $Y t$ is $I(d)$ and $Y t$ is non-stationary but $\Delta Y t$ is stationary where $\Delta Y_{t}=y_{t}-y_{t-1}$ (Cuthbertson, et al., 1995, p.130), an appropriate test for stationarity has been suggested by Dickey and Fuller (Hill, et al., 2001, p.344). According to Gujarati (2003, p.814), the following equations can be used for such a test:

$$
\begin{aligned}
& y_{t}-y_{t-1}=\rho y_{t-1}-y_{t-1}+u_{t} \\
& \begin{aligned}
\Delta y_{t} & =(\rho-1) y_{t-1}+u_{t} \\
& =\delta y_{t-1}+u_{t}
\end{aligned}
\end{aligned}
$$

Where $-1 \leq \rho \leq 1, \delta=\rho-1$ and $\Delta$ represents the first-difference operator. In this scenario one is testing the null hypothesis $\delta=0$ if $\rho=1$, that is, there is a unit root. In other words, the time series under consideration is non-stationary if the null hypothesis is true. Moreover, if unit root is ignored equation 6 is estimated, then it can be shown that the distribution of the ordinary least square's (OLS) estimate of $\rho$ is not centred at 1 and the corresponding " $t$ " statistic does not have a student's $t$ distribution and therefore the usual $t$ test for $\rho=1$ does not apply (Ramanathan, 1995, p.553). Instead of a $t$ test, three forms of the $\tau$ (tau) test are used (Gujarati, 2003, p.815).

Practically, the Dickey-Fuller test is applied to regressions using equations 7 to 9 as follows:

$$
\begin{aligned}
& \Delta y_{t}=\delta y_{t-1}+u_{t} ; \\
& \Delta y_{t}=\beta_{1}+\delta y_{t-1}+u_{t} ;
\end{aligned}
$$

$$
\Delta y_{t}=\beta_{t}+\beta_{2} t+\delta y_{t-1}+u_{t}
$$

Where $t$ is the time or trend variable. The difference between 7 and the other two equations lies in the inclusion of the intercept $\left(\beta_{1}\right)$ and a trend term. Equation 7 is the formula for a random walk, 8 the random walk with drift, while 9 represents the random walk with drift around a stochastic trend. If the computed values of the $\mathrm{T}$ statistic in absolute value exceed the critical DF value, the time series in the equation is stationary, but if the calculated i statistic is less than the DF critical value the null hypothesis is not rejected. Thus the time series is non-stationary. Gujarati $(1995, p .719)$ stresses that if the regression is run in the form of 6 , the estimated $\mathrm{T}$ statistic usually has a negative sign. A large negative $\mathrm{T}$ value relative to the critical value is generally an indication of stationarity. Thus one does not fail to reject the null hypothesis of non-stationary in this instance.

\section{Augmented Dickey-Fuller Test (ADF)}

This test suggests that the tau $\tau$ statistic must take larger negative values than usual in order for the null hypothesis $(\delta=$ 0 ), a unit root or non-stationary process to be rejected in favour of the alternative that is $\delta<0$, which indicates a stationary process. To preclude the possibility that the error term in one of the above equations (under DF), are 
autocorrelated, some additional terms are included. These additional terms are usually the lagged values of the dependent variables (Hill et al., 2001, p.344). An important assumption of the DF test, according to Gujarati (2003, p.818), is that the error terms are independently and identically distributed, while the ADF test adjusts the DF test to take care of possible serial correlation in the error terms by adding the lagged and differenced terms of the regressand.

If the error term is found to be autocorrelated under the Dickey-Fuller test, the Augmented Dickey-Fuller test (ADF), which is a test that includes additional lagged terms, is used. In this case, the ADF equation is:

$\Delta y_{t}=\beta_{1}+\beta_{2} t+\delta y_{t-1}+\alpha_{i} \sum_{i=1}^{m} \Delta y_{t-1}+\varepsilon_{t}$.

Where $\Delta y_{t}=\left(y_{t-1}-y_{t-2}\right), \Delta y_{t}=\left(y_{t-2}-y_{t-3}\right)$ and so on and $\varepsilon$ is the white noise term, while $\mathrm{m}$ stands for the lag length. The ADF test is comparable to the simple DF test, but the slight difference is that the first involves adding an unknown number of lagged first differences of the dependent variable to capture autocorrelation in omitted variables that would otherwise enter the error term. However, as emphasized by Harris (1995, p.34), it is also very important to select the appropriate lag length; too few lags may result in over-rejecting the null hypothesis when it is "true" while too many lags may reduce the power of the test. One should make sure that the sample size is enough with a high probability of obtaining accurate results. This concurs with Keller and Warrack (2003) and Mann (2004), who confirmed that the results from a sample size equal to or greater than, 30 make more sense than the ones from a small sample size $(<30)$.

\section{Testing for Cointegration}

The theory of cointegration was developed in the 1980s and 90s by several researchers such as Engle and Granger (1987), Johansen (1988) and Engle and Yoo (1987) and others. Similarly, Robinson and Marinucci (2003, p.334) reconfirm that cointegration analysis has been developed as a major theme of time series econometrics and generated much applied interest, prompting considerable methodological and theoretical developments during the 1990s. Therefore the cointegration method has become a useful econometric tool (Johansen and Juselius, 1990, p.192). According to Harris (1995, p.22), "if a series must be differenced $d$ times before it becomes stationary, then it contains $d$ unit roots and is said to be integrated of order $d$, denoted $I(d)$." But the question to be asked is why are observed time series integrated? Granger and Newbold (1974, p.115) reply: "...variables are integrated either because they are driven by other integrated variables, or because the dynamic processes generating them contain autoregressive roots of unity; in other words, unit roots may be found in either the marginal or conditional subsystems, or, of course, both." In the case where residuals are expressed, as a linear combination of the variables which are all I(1), this linear combination will itself be I(1), but it would be desirable to obtain residuals that are $I(0)$. This can only be achieved if the variables are cointegrated (Brook, 2002).

\section{Engle-Granger and Augmented Engle-Granger Test}

The Engle-Granger test is one of the methods that are used when the data available are thought to be non-stationary and possibly cointegrated. As a rule, non-stationary time series should not be used in regression models, to avoid the problem of spurious regression (Hill et al., 2001, p.346). If time series data are I(1) or non-stationary, then we estimate the cointegrating regression using ordinary least squares. However, it is not possible to perform any inferences on the coefficient estimates from the usual regression. One can only estimate the parameter values after making sure that the residuals of the cointegrating regression are $I(0)$, and if so then one can proceed to the next step, which is the error correction mechanism (ECM). If the residuals are I(1), one cannot use the estimated standard errors and the associated $t$ values of the estimated coefficients (Gujarati, 1995, p.727), but a model containing only first differences should be estimated (Brooks, 2002). The different orders of integration imply a hidden assumption of the error term being nonstationary.

An important point with this testing method is that if two individual I(1) variables are co-integrated, when a linear combination of both variables is $I(0)$, then their entry into the estimating equation will not create spurious results (Kennedy, 1998, p.228). To avoid the problem of a meaningless regression, the Engle-Granger test is used. From this model the residuals are estimated and a unit root test is utilized to find out whether variables co-integrate. This determines whether or not there is a long-run relationship between them. If this test does not give a satisfactory result, the Augmented Engle-Granger (AEG) test is used. However, the difference between Engle-Granger and AEG is to run a 
cointegration regression, by estimating the Augmented Dickey-Fuller regression, but with the AEG the lagged values of the residuals are applied (Gujarati, 1995). The lesson to be retained from using the Engle-Granger test is that one must be aware of the fact that it does not prove that there is really a long-run relationship. According to Charemza and Deadman (1993, p.157), a strong belief in a long-run equilibrium relationship between the variables must be supported by relevant economic theory.

\section{Cointegration Regression Durbin-Watson (CRDW)}

An alternative, easy and a quicker method of finding out whether dependent and independent variables are cointegrated is the Durbin-Watson test, whose critical values are first introduced by Sagan and Bhargava (1983). Charemza and Deadman (1993, p.153) point out that the distribution of the cointegration regression Durbin-Watson test is not fully investigated and its critical values are not known. Based on 10000 simulations formed from 100 observations each, Gujarati $(1995$, p.728) notes that the 1,5 and 10 per cent critical values of $d$ (not DW) to test the null hypothesis that $d=$ 0 are $0.511,0.386$ and 0.322 , respectively. Therefore the alternative hypothesis of cointegration will be rejected if the computed $d$ value is smaller than, say, 0.386 at the 5 per cent level and if it is greater than the critical value, the null hypothesis is accepted, which means that the variables are cointegrated.

It should be remembered that the power of a cointegration regression test depends positively on the goodness of fit of the ordinary least squares estimate of the long-run relationship of the specified model. From this, Banerjee et al. (1986) propose a simple 'rule of thumb' for a quicker evaluation of the cointegration hypothesis: that if computed $d$ value for the residuals is smaller than the coefficient of determination $\left(R^{2}\right)$ the apparent significance of a statistic relationship is likely to be false. This is an indication that the model has a problem of autocorrelation. If the Durbin-Watson value is above $\mathrm{R}^{2}$, there is a higher probability that cointegration needs investigation.

\section{Error Correction or Equilibrium Correction Mechanism (ECM)}

The error correction model was initially used by Sargan (1984), Hendry and Anderson (1977) and Davidson et al. (1978) to make adjustments in a dependent variable which depends not on the level of some explanatory variable, but to the extent to which an explanatory variable deviates from an equilibrium relationship with the dependent variable. In other words, if there is cointegration between variables and there is a possibility that in the short-run there may be disequilibrium one uses this model. Therefore, to correct this disequilibrium, an error correction mechanism hopefully pushes the model back towards the long-run equilibrium (Engle and Granger, 1987: 251). The error correction model thus plays an important role, in that it is a force that pulls the error back toward zero as should be the case when moving back towards equilibrium.

The error correction model is simply a linear transformation of the autoregressive-distributed lag model. One may ask what its distinguishing feature is. The difference in the error correction modelling is that parameters describe the extent of short-run adjustment to equilibrium are immediately provided by the regression (Benerjee et al., 1993, p.51). Therefore, in practice, the error correction term, which is nothing more than the lagged residuals from the levels regression, $\hat{U}$ and is preferable to other regression methods. The error correction model can be estimated for more than two variables. During periods of disequilibrium, $\hat{U}_{t-1}$ is non-zero and measures the distance real money demand is away from equilibrium during time t. Thus an estimate of the coefficient of $\hat{U}$ will provide information on the speed of adjustment back to equilibrium (Harris, 1995, p.24). Its strict definition is that "it measures the proportion of last period's equilibrium error that is corrected for" (Brooks, 2002, p.391). A large coefficient of error term close to negative one implies a quick adjustment, while a small value close to zero suggests that an adjustment to the long-run steady-state is slow. This makes the equilibrium correction model formulation attractive, because it immediately provides the parameter describing the rate of adjustment from disequilibrium in the short-run (Ericsson and Sharma, 1996, p.26). The conclusion is made from the sign and value of coefficient of error term. With the error coefficient, one can use half-life formula to indicate how long it may take to re-adjust to equilibrium. This can be also checked by a Monte Carlo simulation of same equation with 2000 repeated random samples (Niyimbanira, 2012) and it gives the same results with Johansen Cointegration test.

\section{Conclusion}

This paper discusses problems encountered in time series data and how to overcome them. It shows that regression with 
non-stationary series is generally biased and inconsistent. In other words, regressing one non-stationary series on one another is likely to yield spurious results. However, this paper explains how a cointegration analysis allows one to conduct an econometric analysis using non-stationary variables. According to Harris (1995, p.25), "failure to establish cointegration often leads to spurious regressions which do not reflect long-run economic relationships but, rather, reflect the 'common trends' contained in most non-stationary time series." This paper presents the steps which should be followed: checking for stationarity, testing for unit roots when testing for the order of integration of the residuals from the cointegration regression, using the Dickey-Fuller (DF) test and the augmented Dickey-Fuller (ADF) test. In terms of cointegration testing, this paper focuses on Engle-Granger and Augmented Engle-Granger tests for the long-run relationship between dependant variable and its explanatory variables. For the short-run relationship, the error correction mechanism is used. Therefore there is a useful and meaningful link between the long- and short-run approaches to econometric modelling. Further studies could be conducted by examining usage of half-life formula in economics when one uses time series data.

\section{References}

Banerjee, A., Dolado, J., Hendry, D. and Smith, G. (1986). Exploring Equilibrium Relationships in Econometrics through Static Models: Some Monte Carlo Evidence. Oxford Bulletin of Economics and Statistics, Vol. 48, No. 3, pp. 253-277.

Banerjee, A., Dolado, J., Galbraith, J. and Hendry, D. F. (1993). Cointegration, Error-Correction, and Econometric Analysis of Nonstationary Data: Advanced text in Econometrics. New York, Oxford University Press.

Brooks, C. (2002). Introductory Econometrics for Finance. Cambridge, Cambridge University Press.

Charemza, W. W. and Deadman, D. F. (1993). New Direction in Econometric Practice: General to Specific Modelling, Cointegration and Vector Autoregression. Brookfield, Edward Elgar Publishing Limited.

Cuthbertson, K, Hall, S. G and Taylor, P. M. (1995). Applied Ecometrics Techniques. Ann Arbor, The University of Michigan Press.

Engle, R. F. and Granger, C.W.J. (1987). Co-integration and Error Corrections: Representation, Estimation and Testing. Econometrica, 55(2), 251-276.

Engle, R. F. And Yoo, B. S. (1987), Forecasting and Testing in Cointegrated Systems. Journal of Econometrics, 35, $143-159$.

Ericsson, N. R. and Sharma, S. (1996). Broad Money Demand and Financial Liberalisation in Greece. International Discussion Paper 559 , Board of Governors of the Federal Reserve System (U.S), 1-51

Granger, C. W. J. and Newbold, P. (1974). Spurious Regressions in Econometrics. Journal of Econometrics, 2, 111-120.

Gujarati, D. (1995). Basic Econometrics. 3rd Edition. New York, McGraw Hill.

Gujarati, D. (2003). Basic Econometrics. $4^{\text {th }}$ Edition. New York, McGraw Hill.

Harris, R. (1995). Using Cointegration Analysis in Econometric Modelling. London, Prentice Hall/Harvester Wheatsheaf.

Hawkins, C. and Weber, J. (1980). Statistical Analysis: Application to Business and Economics. New York, Harper \& Row.

Hendry, D.F. and G.J. Anderson (1977). Testing dynamic specification in small simultaneous systems: An application to a model of Building Society behaviour in the United Kingdom. In M.D. Intriligator (Ed.), Frontiers in Quantitative Economics, 3, 361-383.

Hill, R. C, Griffiths, W. E. and Judge, G. G. (2001). Undergraduate Econometrics. 2nd Edition. America, John Wiley \& Sons, Inc.

Johansen, S. (1988). Statistical Analysis of Cointegrating Vectors. Journal of Economic Dynamics and Control, 12, 231-254.

Johansen, S. and Juselius, K. (1990). Maximum Likelihood Estimation and Inference on Cointegration: with Application to theDemand for Money. Oxford Bulletin of Economics and Statistics,52, 169-210.

Kennedy, P. (1996). A Guide to Econometrics. 3rd Edition. Massachusetts, Blackwell Publishers Inc.

Kennedy, P. (1998). A Guide to Econometrics. $4^{\text {th }}$ Edition. Massachusetts, Blackwell Publishers Inc.

Niyimbanira, F. (2012). Real Demand for Money in South Africa: An Econometric Analysis. Saarbrücken, Lambert Academic Publishing.

Ramanathan, R. (1995). Introductory Econometrics: with Applications. 3rd Edition. New York, The Dryden Press.

Sargan, J. D. (1984). Wages and Prices in the United Kingdom: A study in Econometric Methodology. Originally Published in 1964 and Reproduced in Wallis K.F and Hundry D. F eds., Quantitative Economics and Econometric Analysis, Oxford, Basil Blackwell.

Sargan, J. D. and Bhargava, A. S. (1983). Testing Residuals from Least Squares Regression for Being Generated by the Gaussian Random Walk. Econometrica, 51, 153-174.

Shumway, R. and Stoffer, D. S. (2000). Time Series Analysis and Its Applications. Springer Texts in Statistics. New York, SpringerVerlag New York, Inc. 